\title{
Principles of Education Content in Teaching Foreign-language Professional Communication in Non-linguistic Universities
}

\author{
Svetlana Pozdniakova* \\ National Research Technical University, Department of Applied Linguistics, 664074 Irkutsk, Russia
}

\begin{abstract}
In this article, the issues of improving the education content in teaching foreign-language professional communication in a modern university are discussed. It is noted that the Russian system of higher professional education is a constant subject to an active modernization process. Therefore, at the present moment the most important objective of the Educational Policy is to ensure the quality of education, maintaining its fundamental nature and its correspondence to the needs of society and the labor market, to the interests of the individual and the State. With regard to the realities of modern Language Pedagogy, the improved education content in the system of higher professional technical education should correspond to a number of the following fundamental principles: rely on the scientific concept, be directed towards humanization and humanitarization of education; meet the requirements of normative instruments which regulate the learning process; ensure the development of students` personal potential and be authentic.
\end{abstract}

\section{Introduction}

The global concept of education in modern Russia is associated with an active search for new ways and methods to develop self-identity of the future professional, who is able to freely navigate in a multicultural world and is ready for active cross-cultural communication [1]. Radical socio-economic and political changes, the intensification of international relations and the reinforcing of integration processes, all the above-mentioned has a huge impact on the system of higher professional education. For Russia, in order to develop within the framework of an innovative economy based on knowledge and science-intensive technologies, it is necessary to form literate, mobile and highly skilled specialists for the global space [2]. Meeting this objective is possible only if the education system is improving constantly and sustainably, the quality of education is ensured based on maintaining its fundamental nature and its correspondence to the needs of the individual, society and the state. This, in turn, requires raising the quality of education by improving the entire education system, enhancing its flexibility, its efficiency, centering on the development of students individuality, activity, and creativity [3]. The Russian education system needs to shift from a survival mode to a development mode, and at the same time Russian society needs to shift from the monetary maintenance of the education system to investing in it [4].

The modern educational community is in the permanent search of the new ways to improve both the system of vocational education in general, and professionally oriented education. It focuses on the preservation of its foundations and, as well as, on the enhancing its practical and action orientation. In this context, it is assumed that the goal-setting system, as a system of compulsory formation of knowledge, skills, and competencies, is replaced by a complex of professional competences that become means to personal enrichment of a student [5].

\section{Principles of improving education content in teaching foreign-language professional communication}

With the purpose of explaining the particularities of the modernized education content of teaching foreignlanguage in the field of professional communication, it is necessary to focus on the key concept of the presented publication "education content". In general, the concept of "education content of teaching foreign languages", which has been and continue to be under the scrutiny of professors of foreign languages, is a category that interprets pedagogically the goals of teaching foreign languages. If the instructional objective is a multidimensional education, then the content by which the goal is achieved should be multi-component.

In this article, we consider it reasonable to use the theoretical considerations on the education content developed by B.A. Lapidus. His position seems to be the most objective and methodologically rigorous given that it relies on the tangible scientific basis of the fields of linguistics, pedagogy, lexicography, statistics. The scientist's research we are referring to presents a fundamental work devoted to the problems of education 
content in teaching foreign language. The work of B.A. Lapidus is related to the educational environment of a linguistic university; however, a big number of general theoretical questions are universal and just as successfully can be applied in the context of other educational conditions, including a non-linguistic university.

According to the concept of B.A. Lapidus, the education content can be defined as "the totality of what students need to master so that the quality and level of proficiency of the studied language correspond to the objectives of the educational institution" [6].

By maintaining our commitment to this position, we believe the education content should be represented by a bilateral category, which includes both the functional and substantive sides. A functional side of this category should contain the following components: skills and abilities to work with language material; speech skills and abilities, which allow to determine the level of proficiency in a foreign language and its use in communication; learning and compensatory abilities that provide a language acquisition in the educational environment and a culture of communication with native speakers [7].

In turn, the substantive part includes such elements as areas of professional communication, speech situations, topics, texts, linguistic (terminological) materials, as well as knowledge of the national and cultural contexts and realias of the country of the studied language.

With that in mind, we are focusing our research on the basic principles of improving the education content of teaching foreign-language professional communication in a modern non-linguistic university. Further, some of them are explained briefly.

1. The education content should rely on a certain scientific concept.

In a broad sense, the term "concept" is defined as a certain way of understanding and interpreting some phenomenon, together with the main views on this phenomenon [8]. The given definition allows considering the term as a synonym for the notion of "conception of learning", which entails implementation of the overriding idea of teaching as a specific strategy and with the help of one or another instructional method [9]. Through the scientific and methodological literature analysis, it is observed the communicative-cognitive approach is the most extensive, which reflects the specificities of a foreign language as an academic course.

This approach implies that the study of one or other linguistic phenomenon rests on the mental processes and actions, which underlie the comprehension and application of this process in speech. On the one hand, this approach constitutes theoretical justification of communicative technology for teaching foreignlanguage communication. On the other hand, it is associated with such categories as knowledge, cogitation and comprehension processes involved during the process of student's inclusion in a foreign language and its national and cultural realias.

Main provisions of the cognitive approach to language are addressed in the works of E.S. Kubryakova.
According to the author's perception, a leading role is assigned to a human being both in the processes of structuring knowledge about the surrounding world and in the processes of using information that has been previously learned [10]. Consequently, a reliance on cognitive processes occurring in the mind of the learner is a mandatory condition for the effective learning. According to researchers, these processes are defined as a complex of psychological (mental, cognitive) processes of the world perception, "a simple observation of the surrounding world, a categorization of cogitation and speech, and they help to process received information" [11]. Such mental operations contribute to the formation of students individual interests and cognitive abilities, to the development of abilities to rationally find a way out of intellectually difficult situations, to the capacity consciously organize a personal educational activity. This, in turn, implies abandoning the outdated system of monotonous exercises aimed at automation and revision of strictly fixed structures and switching to a conceptual level of mastering the material, taking into account the qualitative differences in various cultures.

2. The education content should be directed towards humanization and humanitarization of education.

The humanistic orientation of all types of educational and instructional activities becomes the basis of the state educational policy. This implies the need to introduce goal-setting mechanisms in the education sector that would reflect the harmony and unity of the universal and particular Russian mental values of the individual and society. Also, it would contribute to the formation of a systematic humanistic outlook based on the awareness of the mankind`s unity, the need to cognize and enrich the higher spiritual and cultural values [12].

As far as is known, the humanitarization of vocational education in higher education is ensured by including in the educational content a general culture competent, the subject "Foreign Language" forms one of its parts. The formation of general cultural competences is aimed at the interrelated socio-cultural and professional development for a student, at creating conditions for his sustainable personal enrichment and self-realization in sociocultural and professional activities.

In modern conditions of a multidisciplinary university, the study of foreign languages has become an important key for the sustainable social development of the future professional. As a result, in the educational program of a non-linguistic university, this academic course transforms from the general cultural component into a professionally significant one of the graduate's preparation, which determines the content and level of his professional competence [13].

In this context, we focus on the subject-object nature of the relation, considering the problem of the education content of teaching foreign-language communication through the prism of humanizing the learning process. The mission of the subject and activity approach is to create comfortable conditions for the formation and development of an individual, self-developing, selforganizing and self-cultivating personality. As E.G. 
Tareva points out, "the student is given special importance, has a particular responsibility for the results of academic work, for achieving a proper level of training in foreign-language communication" [14]. In her later publications, the author presents the transformation of educational purposes "from the extra-subjective (teaching foreign language), it has become the subjective (the formation of communicative competence as the ability of the learner)" [15].

Therefore, according to the conception of N.I. Almazova, who in her works examines the main features of foreign language education in Russian universities, it can be stated that the humanitarian educational paradigm, applied in the modern educational sector, should be anthropocentric, aimed at the dialogue of all participants of the educational process and implemented in all components of the education content [16].

3. The education content should meet the requirements of normative instruments which regulate the learning process in a multi-disciplinary university.

It is well known that in an education-related situation, particular relevance is given to a set of government documents designed to serve as a model for implementing a new approach to highlight pragmatic aspects of teaching foreign languages. In the context of the regulatory framework, the Federal State Educational Standard of Higher Professional Education is of particular importance. This standard determines the general part of the education content in academic courses in the presence of various educational programs, plans, textbooks, etc. An important characteristic of the Federal State Educational Standard of Higher Professional Education is its competence base, which is strictly focused on forming the students` competences as learning outcomes.

At the present stage, the competency-based approach in the engineering education is presented as a "description of learning outcomes in the language of competences" of the future graduate. These outcomes can be represented as a dynamic body of knowledge, skills, abilities, values necessary for the efficient professional and social life and personal development of graduates. The graduates are obliged to master it and demonstrate it after completing a part or all of the educational programs of the academic course [17].

The main educational program of the academic course is designed to specify the substantive aspects of the standard. In the part dedicated to the subject "Foreign Language", the program reflects the consistent education process of teaching professionally oriented foreignlanguage, describes the education content, as well as the methods and techniques of teaching, taking into account the particularities of teaching language in a technical university.

The implementation of listed above normative documents, which regulate the educational process in universities, is a necessary condition for improving the quality of training young specialists.

4. The education content should ensure the achievement of pragmatic, cognitive and general educational aspects of educational purposes.
Foreign language training in the system of higher professional technical education is aimed at the formation of graduates with such abilities that will enable them to use a foreign language as a tool for communication in a dialogue of cultures, as well as means of scientific and technical communication [18].

In modern educational conditions, the teaching process of foreign-language professional communication is seen from three aspects: pragmatic, cognitive and general educational. The pragmatic aspect is connected with students forming foreign communicative competences at different levels, which allow them to use a foreign language for addressing the challenges occurring in interpersonal and intercultural interactions. This aspect is related to the formation of a set of competences, which includes knowledge, skills, abilities, capacity and readiness to engage in the intercultural interaction with members of a different culture. This set allows successfully hold a conversation in a foreignlanguage. The complex of knowledge, skills and abilities should also include student's ability to perform selfeducation and self-improvement with the help of a foreign language, and the ability to satisfy cognitive interests with the help of a new language code.

The cognitive aspect falls within the ambit of such categories as knowledge, cogitation, perception and understanding processes involved in students 'initiation into a new foreign language, into the achievements of national cultures (their own and foreign cultures), into the reflection of the mother tongue and native culture in the mirror of a different one. Learning about another culture takes place in the process of perception of another's "world view", in its interpretation through the images of national consciousness. The cognitive aspect of the educational purposes also means the students' skills and habits development in using rational methods of mastering the studied language, which enable them to master a foreign language creatively, economically and purposefully.

And lastly, the general educational aspect of learning objectives means considering the education content from the perspective of its educational impact on the student's personality.

5. The core of the education content should be based on the authenticity principle.

As mentioned above, the concept of "education content of teaching foreign-language professionally oriented communication" has a dual structure, the basic part of which should correspond to the authenticity principle.

In the modern methodology, there is a determined classification of authentic materials. This classification is considered acceptable for the educational purposes in a technical university. The classification of such materials is briefly summarized below.

1. Didactized materials are defined as a didactic material created by a native speaker. Its primary goal is to show structural and systemic phenomena of the language in artificially constructed conditions. In the context of a non-linguistic university, this type of material can be mainly applied depending on the 
students` level of proficiency in the studied language and on the training phase.

2. Semi-authentic materials. Those are materials adapted for educational purposes in order to help students gradually adapt to the natural behavior of native speakers. As I.I. Khaleeva points out, this category of materials can be used "to form a linguistic picture of the world and, at the same time, to fulfill the function of "substance" in the conceptual systems of a learner" [19].

3. Authentic materials are defined as materials that native speakers produce for native speakers. These materials can be original texts created for real conditions and not for the simulated learning situation.

In the context of a technical university, this particularity of the education content of teaching professionally oriented foreign language communication is manifested in the fact that the educational material should present samples of native speakers' natural language, should introduce students to the typical rules of their verbal behavior, national and cultural identity of the country of the studied language.

6. The education content should correspond to the students`interests and needs.

This characteristic of the education content of teaching foreign-language professional communication is observed in the creating a model of a specialist. The model should include an important component of professional knowledge, skills, and abilities to perform professional activities, which represent the qualification requirements a specialist should poses. Since effective professional communication within the framework of international cooperation is impossible without knowledge, skills, and abilities in the occupational areas, therefore, in this context, the model acts as a result of learning the education content in general and, in particular, the educati0on content of teaching foreign language communication.

\section{Conclusions}

To summarize the work, we could confirm that the education content is one of the important components of the educational system of teaching foreign-language communication. Highlighting its special professionally oriented characteristics makes it possible to specify and clearly define the educational goals of teaching students of the areas of the technical expertise a foreign language. Accordingly, a special vocational-oriented language training becomes a guarantee of graduates getting social and professional mobility and, also, is a key to the successful work on the world's standards level and to their further professional growth.

\section{References}

1. Russian Federation Government Order from 29 of November 2014 The State Youth Policy of the Russian Federation for the period up to 2025

2. The concept for a long-term socio-economic development of the Russian Federation (Ministry of Economic Development, Moscow, 2008)
3. Federal Law On Education in the Russian Federation num. 273-FZ edition of 29 December 2017

4. Leading trends in the development of modern education, Electronic resource: URL http://www.profile-edu.ru/vedushhietendencii-v-razvitii-sovremennogo-razovaniyaosnovnye-protivorechiya-page-1.html

5. I. A. Zimniaia, Key competences as the effectivetarget basis of competence approach in education (Research Center for Quality Problems in Training Specialists, Moscow, 2004)

6. B. A. Lapidus, Problems of education content of teaching foreign language in a linguistic university (Vysshaia shkola, Moscow, 1986)

7. N. D. Galskova, Modern methods of teaching foreign languages (Glossa, Moscow, 2000)

8. Big encyclopedic dictionary (Norint, Moscow, 2001)

9. I. L. Kolesnikova, O. A. Dolgina, English-Russian terminology reference book on the methodology of teaching foreign languages (Cambridge University Press, St. Petersburg, 2001)

10. E. S. Kubriakova, Language and cognition: On the way of obtaining knowledge about language: Parts of speech from the cognitive point of view. The role of language in the way of conceiving the world (Yazyki slavianskio kultury, Moscow, 2004)

11. Y. S. Stepanov, Constants. Dictionary of Russian culture. Research experience (Languages of Slavic Culture, Moscow, 1997)

12. O. M. Smetanina, Foreign languages at school 5, 2126, (2010)

13. N. F. Koriakovtseva, Humanitarian Educational Environment in a Technical University, 8-10, (2016)

14. E. G. Tareva, Vestnik ISLU 6, 5-11, (2006)

15. E. G. Tareva, Humanitarian Educational Environment in a Technical University, 309-311, (2016)

16. N. I. Almazova, V. Ya. Kikot, St. Petersburg State Polytechnic University Journal, Humanities and Social Sciences 3, 9-16, (2013)

17. E. D. Alisultanova, Competence approach in engineering education (Academia Estestvoznaniya, Moscow, 2010)

18. N. A. Kobzeva, Young Scientist, 2011, Electronic resource: URL https://moluch.ru/archive/26/2790/

19. I. I. Khaleeva, Foundations of the theory of teaching the understanding of a foreign language (MSLU, Moscow, 1989) 